\title{
A Case of Incidentally Discovered Subclinical Cushing Syndrome in a Patient with Chronic Fatigue and Anxiety

\author{
Kyung-Jee Nam, Yun-Jin Kim ${ }^{1}$, Sang-Yeoup Lee, Jeong-Gyu Lee ${ }^{1}$, \\ Young-Hye Cho, Yu-Hyun Lee ${ }^{1}$, Eun-Jung Choi, Young-Jin Tak ${ }^{1}$, \\ Dong-Won $\mathrm{Yi}^{2}$, Sung-Woo Park ${ }^{3}$, Dong-Wook Jeong*
}

Department of Family Medicine, Pusan National University Yangsan Hospital, Yangsan; ${ }^{1}$ Department of Family Medicine, Pusan National University Hospital, Busan; ${ }^{2}$ Diabetes Center and Endocrine Clinic, Departments of Internal Medicine and ${ }^{3}$ Urology, Pusan National University Yangsan Hospital, Yangsan, Korea

Subclinical Cushing syndrome (SCS) is a hypothalamic-pituitary-adrenal axis abnormality characterized by autonomous cortisol secretion in patients with no typical signs or symptoms of Cushing syndrome. SCS patients may have adverse metabolic and cardiovascular effects due to slight, but continuous glucocorticoid secretion. Glucocorticoids also affect behavior, mood, neural activity, and a number of specific biochemical processes in the central nervous system. Here, we report a case of SCS due to an adrenal incidentaloma in a hypertensive diabetic patient who presented with chronic fatigue and anxiety that disappeared after the removal of the adrenal adenoma.

Keywords: Subclinical Cushing Syndrome; Adrenal Incidentaloma; Chronic Fatigue; Anxiety

\section{INTRODUCTION}

Autonomous cortisol secretion in patients with no typical signs or symptoms of hypercortisolism is defined as "subclinical Cushing syndrome" (SCS). An increased frequency of hypertension, central obesity, impaired glucose tolerance or diabetes, hyperlipemia, and osteoporosis have been described in patients with SCS, possibly because these patients are exposed to a

Received: January 23, 2013, Accepted: June 5, 2013

${ }^{*}$ Corresponding Author: Dong-Wook Jeong

Tel: +82-55-360-1442, Fax: +82-55-360-1592

E-mail: dwjeong75@hanmail.net

Korean Journal of Family Medicine

Copyright (C) 2013 The Korean Academy of Family Medicine

(a) This is an open-access article distributed under the terms of the Creative Commons Attribution Non-Commercial License (http://creativecommons.org/licenses/by-nc/3.0) which permits unrestricted noncommercial use, distribution, and reproduction in any medium, provided the original work is properly cited. slight, but chronic cortisol excess. ${ }^{1,2)}$ SCS is prevalent in 79 people per $100,000,{ }^{3)}$ and in $5 \%$ to $20 \%$ of adrenal incidentalomas. ${ }^{4-7)}$ Improvements in abdominal imaging technologies have led to increased detection of adrenal incidentalomas and are thus expected to increase the frequency of diagnosing SCS. In this study, we report a case of SCS due to an incidental adrenal mass in a hypertensive diabetic patient who presented with anxiety and chronic fatigue without the typical symptoms of Cushing syndrome.

\section{CASE REPORT}

A 51-year-old woman visited the department of family medicine, Pusan National University Yangsan Hospital, Yangsan, Korea, complaining of a 2-year history of anxiety and fatigue. She had previously visited a cardiologist and was diagnosed with early-stage diabetes with known hypertension, and prescribed 
alprazolam and lorazepam. However, her symptoms were not alleviated, and fatigue, weakness, and dizziness developed. She also visited a neurologist and rehabilitation specialists, but these symptoms persisted. Her underlying diseases included 10 years of hypertension, 2 years of diabetes, and lumbar neuropathy following surgery for spinal stenosis 2 years ago. She was also a chronic hepatitis B carrier. Her family history did not yield any remarkable findings, and she had no history of smoking or drinking. On physical examination, her blood pressure was 149/91 $\mathrm{mm} \mathrm{Hg}$; pulse, 74 beats/min; temperature, $36.5^{\circ} \mathrm{C}$; and respiratory rate, 20 breaths $/ \mathrm{min}$. Her weight was $47.9 \mathrm{~kg}$, and her body mass index was $19.8 \mathrm{~kg} / \mathrm{m}^{2}$. The patient was in good condition and her chest and abdomen were normal. There was no peripheral edema. The results of her neurological examination were normal.

The results of routine laboratory blood tests and thyroid function tests were normal. Routine urine analysis revealed microscopic hematuria (red blood cell $[\mathrm{RBC}]>30 / \mathrm{HPF}$ ) and rechecked value was RBC 3-5/HPF. Abdominal ultrasonography revealed no specific findings except for mild fatty liver. Computed tomography (CT) was performed for the unexplained hypertension and differential diagnosis of hematuria. CT showed a right renal stone, and a well-circumscribed and homogeneous $2.7 \mathrm{~cm}$-sized mass containing a fatty component in the left adrenal gland on a non-contrast-enhanced CT, suggesting adrenal adenoma (Figure 1). There was no specific finding on endoscopy except for erosive gastritis. Dual-energy X-ray absorptiometry revealed osteopenia.

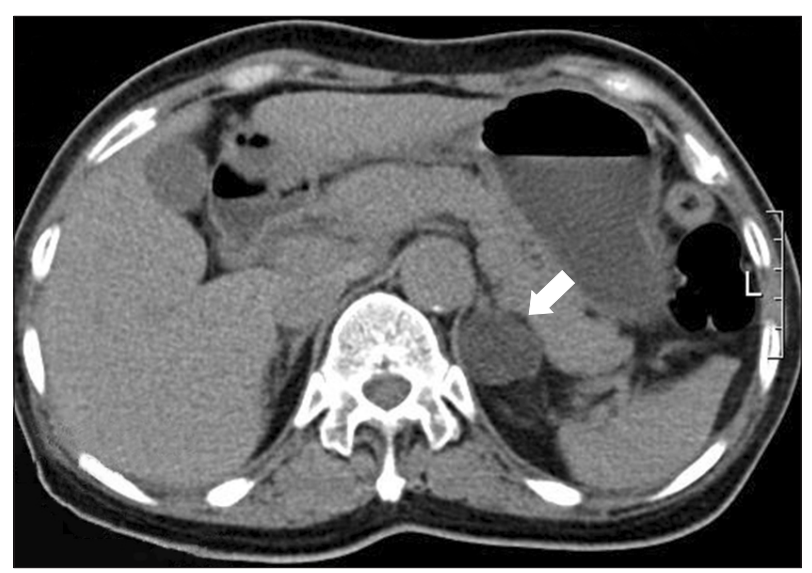

Figure 1. Computed tomography showed a well-circumscribed and homogeneous $2.7 \mathrm{~cm}$ sized mass containing a fatty component in the left adrenal gland, suggesting adrenal adenoma (arrow).
The patient received endocrine evaluation for the differential diagnosis of adrenal incidentaloma. Baseline serum cortisol at 8:00 a.m. (17.17 $\mu \mathrm{g} / \mathrm{dL})$ was normal but the 24-hour excretion of urinary free cortisol (UFF) $(100.54 \mu \mathrm{g})$ and serum basal 17-hydroxyprogesterone $(19.0 \mathrm{mg} / \mathrm{d})$ were elevated. A lowdose dexamethasone suppression test (DST) (0.5 mg orally, 4 times a day for 2 days, with measurement of serum cortisol and other steroids at 8:00 a.m. the following morning, and determination of UFF) failed to suppress the serum cortisol level $(14.78 \mu \mathrm{g} / \mathrm{dL})$ and the 24-hour UFF $(282.56 \mu \mathrm{g})$. Highdose DST ( $2 \mathrm{mg}$, 4 times a day for 2 days) also failed to suppress the serum cortisol level $(16.82 \mu \mathrm{g} / \mathrm{dL})$ and the 24-hour UFF $(186.62 \mu \mathrm{g})$. The 24-hour urinary excretion of catecholamines and metanephrine, measured to rule out pheochromocytoma, showed normal results (epinephrine $1.0 \mu \mathrm{g} / \mathrm{d}$, norepinephrine $54.5 \mu \mathrm{g} / \mathrm{d}$, and metanephrine $0.672 \mathrm{mg} / \mathrm{d}$ ). Renin plasma activity was $0.26 \mathrm{ng} / \mathrm{mL} / \mathrm{h}$, aldosterone was $9.63 \mathrm{pg} / \mathrm{mL}$, and the aldosterone renin activity ratio was normal (0.96), excluding an aldosterone-producing adenoma. Therefore, the adrenal mass on CT was diagnosed as a cortisol-producing tumor. The tumor was surgically removed by left laparoscopic adrenalectomy. The pathological diagnosis was adrenocortical adenoma, $3 \times 2 \mathrm{~cm}$ in size, without any evidence of malignancy.

After the resection of the adrenal adenoma, the patient' $s$ general condition improved and self-reported anxiety and dizziness disappeared. Her blood pressure stabilized with fewer antihypertensive medications, and her hemoglobin Alc level decreased to $5.3 \%$ after 5 months. She was followed up with supplemental prednisolone $5 \mathrm{mg} / \mathrm{d}$ to treat a suppressed hypothalamic pituitary axis (baseline serum cortisol at 8:00 a.m., $2.78 \mu \mathrm{g} / \mathrm{dL}$; adrenocorticotropic hormone, $11.1 \mathrm{pg} / \mathrm{mL}$ ).

\section{DISCUSSION}

An adrenal "incidentaloma" is an adrenal mass that is discovered serendipitously during a radiologic examination performed for clinical conditions other than adrenal disease. ${ }^{8)}$ It is found in $6 \%$ of autopsies. ${ }^{8,9)}$ The widespread use of abdominal ultrasonography (US), CT, and magnetic resonance imaging has increased the detection of adrenal incidentaloma (range, $0.4 \%$ to $6 \%$ of all US and CT). ${ }^{10-12)}$ Most adrenal incidentalomas are non- 
functioning tumors (range, 70\% to 94\%). However, some secrete hormones including cortisol (range, $5 \%$ to $20 \%$ ), catecholamines (range, $3 \%$ to $10 \%$ ), aldosterone (1\%), and the sex hormone (range, $0 \%$ to $11 \%){ }^{13,14)}$ Recent reports suggest that up to $20 \%$ of patients with an adrenal incidentaloma have some form of subclinical hormonal dysfunction and may represent a population at higher risk for metabolic disorders and cardiovascular disease. ${ }^{11)}$ Adequate evaluation and treatment are necessary to identify functioning or malignant tumors, which are generally resected.

SCS is a hypothalamic-pituitary-adrenal (HPA) axis abnormality defined as autonomous cortisol secretion in patients with no typical signs or symptoms of hypercortisolism such as moon face, buffalo hump, or purple striae. Although whether subclinical hypercortisolism progresses to overt Cushing syndrome has not yet been established, the progression toward overt Cushing syndrome seems to occur only rarely. ${ }^{6,15,16)}$ Therefore, SCS is a more appropriate term than preclinical Cushing syndrome. SCS patients may have adverse metabolic and cardiovascular effects including hypertension, obesity, diabetes mellitus, and osteoporosis, due to the continuous glucocorticoid secretion. ${ }^{2,17-20)}$ Glucocorticoids also affect behavior, mood, neural activity, and a number of specific biochemical processes in the central nervous system. ${ }^{17)}$ The presence of depressive symptoms can be an early manifestation of HPA axis abnormalities and Cushing syndrome. ${ }^{21)}$ Normalization of cortisol levels generally improves depressive as well as other disabling psychological symptoms. ${ }^{21-23)}$ The progression towards overt clinical Cushing syndrome is rare and not obvious. ${ }^{8,24-26)}$ Adrenalectomy is considered for patients with disorders that are potentially attributable to autonomous glucocorticoid secretion. A patient with SCS requires glucocorticoid therapy perioperatively, because of the risks of adrenal insufficiency, hemodynamic crisis, and death. ${ }^{5)}$ The need for longer-term replacement and slow tapering of exogenous glucocorticoids should be assessed postoperatively. Long-term prospective studies are needed for a better understanding of the natural history of SCS and for better guidance on decisions regarding surgical intervention.

In this case, our patient had a functioning tumor, and resection was performed as treatment. After the resection of the adenoma, the patient showed a decreased cortisol level with improvement in hypertension and glycemic control. Some case series have demonstrated that unilateral adrenalectomy induces weight loss and improvement in hypertension or glycemic control or both, as well as the normalization of markers of bone turnover in patients with SCS. ${ }^{17,19,27)}$

The patient's fatigue and anxiety symptoms, as well as metabolic and cardiovascular disorders disappeared after the removal of the adrenal adenoma. As the diagnosis of SCS was delayed, she was mistakenly considered as needing psychiatric treatment. Due to the inconvenience of hormonal studies, patients with vague depressive symptoms such as chronic fatigue or anxiety without typical features of specific endocrine disease can be easily overlooked without proper endocrine assessment. However, the presence of depressive symptoms such as fatigue and anxiety can be an early manifestation of HPA axis abnormalities. ${ }^{21,28)}$ Therefore, in cases of unexplained chronic fatigue or anxiety with concomitant metabolic and cardiovascular disorders, assessment of the HPA axis should be considered.

\section{CONFLICT OF INTEREST}

No potential conflict of interest relevant to this article was reported.

\section{ACKNOWLEDGMENTS}

This study was supported by the Research Institute of Convergence of Biomedical Science and Technology, Pusan National University Yangsan Hospital 2013.

\section{REFERENCES}

1. Russi S, Blumenthal HT, Gray SH. Small adenomas of the adrenal cortex in hypertension and diabetes. Arch Intern Med (Chic) 1945;76:284-91.

2. Tauchmanova L, Rossi R, Biondi B, Pulcrano M, Nuzzo V, Palmieri EA, et al. Patients with subclinical Cushing' s syndrome due to adrenal adenoma have increased cardiovascular risk. J Clin Endocrinol Metab 2002;87:4872-8.

3. Reincke M. Subclinical Cushing's syndrome. Endocrinol Metab Clin North Am 2000;29:43-56. 
4. Young WF Jr. Clinical practice: the incidentally discovered adrenal mass. N Engl J Med 2007;356:601-10.

5. McLeod MK, Thompson NW, Gross MD, Bondeson AG, Bondeson L. Sub-clinical Cushing's syndrome in patients with adrenal gland incidentalomas: pitfalls in diagnosis and management. Am Surg 1990;56:398-403.

6. Terzolo M, Bovio S, Reimondo G, Pia A, Osella G, Borretta G, et al. Subclinical Cushing's syndrome in adrenal incidentalomas. Endocrinol Metab Clin North Am 2005;34: 423-39, $x$.

7. Terzolo M, Reimondo G, Bovio S, Angeli A. Subclinical Cushing's syndrome. Pituitary 2004;7:217-23.

8. Young WF Jr. Management approaches to adrenal incidentalomas: a view from Rochester, Minnesota. Endocrinol Metab Clin North Am 2000;29:159-85, x.

9. Kloos RT, Gross MD, Francis IR, Korobkin M, Shapiro B. Incidentally discovered adrenal masses. Endocr Rev 1995;16: 460-84.

10. Geelhoed GW, Druy EM. Management of the adrenal “incidentaloma”. Surgery 1982;92:866-74.

11. Katz RL, Shirkhoda A. Diagnostic approach to incidental adrenal nodules in the cancer patient: results of a clinical, radiologic, and fine-needle aspiration study. Cancer 1985;55: 1995-2000.

12. Luton JP, Billaud L, Benabed K, Guilhaume B, Bertagna $\mathrm{X}$, Louvel A, et al. Adrenomegaly and other masses of the adrenal area: diagnostic and therapeutic approaches. Ann Endocrinol (Paris) 1988;49:348-52.

13. Grumbach MM, Biller BM, Braunstein GD, Campbell KK, Carney JA, Godley PA, et al. Management of the clinically inapparent adrenal mass ("incidentaloma"). Ann Intern Med 2003;138:424-9.

14. Mansmann G, Lau J, Balk E, Rothberg M, Miyachi Y, Bornstein SR. The clinically inapparent adrenal mass: update in diagnosis and management. Endocr Rev 2004;25:309-40.

15. Siren J, Tervahartiala P, Sivula A, Haapiainen R. Natural course of adrenal incidentalomas: seven-year follow-up study. World J Surg 2000;24:579-82.

16. Barzon L, Fallo F, Sonino N, Boscaro M. Development of overt Cushing's syndrome in patients with adrenal incidentaloma. Eur J Endocrinol 2002;146:61-6.

17. Erbil Y, Ademoglu E, Ozbey N, Barbaros U, Yanik BT,
Salmaslioglu A, et al. Evaluation of the cardiovascular risk in patients with subclinical Cushing syndrome before and after surgery. World J Surg 2006;30:1665-71.

18. Chiodini I, Tauchmanova L, Torlontano M, Battista C, Guglielmi G, Cammisa M, et al. Bone involvement in eugonadal male patients with adrenal incidentaloma and subclinical hypercortisolism. J Clin Endocrinol Metab 2002; 87:5491-4.

19. Rossi R, Tauchmanova L, Luciano A, Di Martino M, Battista C, Del Viscovo L, et al. Subclinical Cushing's syndrome in patients with adrenal incidentaloma: clinical and biochemical features. J Clin Endocrinol Metab 2000;85:1440-8.

20. Terzolo M, Pia A, Ali A, Osella G, Reimondo G, Bovio S, et al. Adrenal incidentaloma: a new cause of the metabolic syndrome? J Clin Endocrinol Metab 2002;87:998-1003.

21. Sonino N, Fava GA. Psychiatric disorders associated with Cushing's syndrome: epidemiology, pathophysiology and treatment. CNS Drugs 2001;15:361-73.

22. Jeffcoate WJ, Silverstone JT, Edwards CR, Besser GM. Psychiatric manifestations of Cushing's syndrome: response to lowering of plasma cortisol. QJ Med 1979;48:465-72.

23. Dorn LD, Burgess ES, Friedman TC, Dubbert B, Gold PW, Chrousos GP. The longitudinal course of psychopathology in Cushing's syndrome after correction of hypercortisolism. J Clin Endocrinol Metab 1997;82:912-9.

24. Barzon L, Sonino N, Fallo F, Palu G, Boscaro M. Prevalence and natural history of adrenal incidentalomas. Eur J Endocrinol 2003;149:273-85.

25. Barzon L, Scaroni C, Sonino N, Fallo F, Paoletta A, Boscaro M. Risk factors and long-term follow-up of adrenal incidentalomas. J Clin Endocrinol Metab 1999;84:520-6.

26. Barzon L, Scaroni C, Sonino N, Fallo F, Gregianin M, Macri C, et al. Incidentally discovered adrenal tumors: endocrine and scintigraphic correlates. J Clin Endocrinol Metab 1998;83:5562.

27. Emral R, Uysal AR, Asik M, Gullu S, Corapcioglu D, Tonyukuk $\mathrm{V}$, et al. Prevalence of subclinical Cushing's syndrome in 70 patients with adrenal incidentaloma: clinical, biochemical and surgical outcomes. Endocr J 2003;50:399-408.

28. Brown ES, Varghese FP, McEwen BS. Association of depression with medical illness: does cortisol play a role? Biol Psychiatry 2004;55:1-9. 